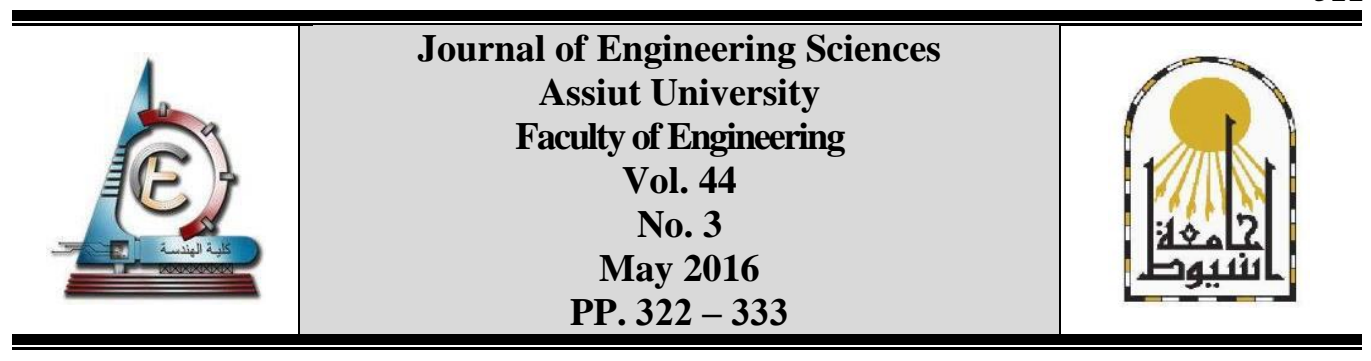

\title{
THE IMPACT OF LAND FORM ON URBAN IDENTITY; EL SHAMIYA PROJECT, MAKKAH, SAUDI ARABIA
}

\author{
Salma S.El-Esawy ", Khalid S. Al-Hagla, Zeyad T. El Sayad \\ Faculty of Engineering, Alexandria University, Alexandria, Egypt.
}

Received 6 April 2016; Accepted 12 May 2016

\begin{abstract}
The aim of this paper is to clarify the relationship between urban identity and landform. It discusses the aspects of urban identity from the system approach then the impact of landform on these aspects i.e. spatial experience and cultural representation is determined. This research is performed in light of recent urban development that takes place in Makkah`s centre. This area is undergoing development that affects its landform configuration. A comparative analysis is conducted between the old Shamiya district and new Shamiya project to examine the changes of its identity. This comparative analysis is based on space syntax theory which is applied using the Rhinoceros $5 \circledR$ program-grasshopper plugin. The results show that highland strengthens the place identity arising from cultural representation and weakens the degree of city legibility.
\end{abstract}

Keywords: Urban Identity-Landform-Makkah-El Shamiya- space syntax.

\section{Introduction}

Identity is founded on a symbolic reciprocal interaction by an ecological relation linked to a specific location that provides discrimination and identification. Likewise, space that evokes a sense of identity provides the backbone to the community and its identity [6]. Thus, Place identity is an indicator of coherence in dynamic processes among landscape structures and culture [4]. According to Alexander (1979) physical patterns affect the intangible action in these patterns and vice versa. In other words, if the place evokes a sense of identity, this sense drives an action. Such action keeps the continuous interaction between the physical environment and social life in harmony because the place image reflects the communities' experiences, beliefs and values. However, the urban development that takes place in some countries raises a question about how physical pattern of urban environment affects the urban identity. Specifically, landform as being a part of the dimensions affecting city`s physical pattern and subsequently, its urban identity [2].

System approach is selected to study the relationship between the tangible aspect (landform) and the intangible aspect (urban identity). The system approach is an approach that considers ecological and cognitive aspects of the inhabitants in the design process [19]. Bennett (1993) illustrates that systems depend on identifying structures and patterns of specific objects. In his study "The First eight systems", he explains that the general rule of the world cannot change unless there are actions and relations. He clarifies them through the triad system: (1) 
initiating (2) characterizing (3) outcome. The core element of the triad system is "impulse"(action) which leads to three terms (1) The Initiating term (2) The characterizing term (3) outcome term. Impulse is suggested as a sense of force or motivation that blends with two other impulses of the triad, leads to a specific action or process. To identify specific characters of each impulse, Bennett uses terms "initiating" for impulses that act or initiates, "characterizing" for impulses that react or resist and "outcome" to affirm receptive of impulse. Impulses might be brought together in a particular action or dynamic process. In the human experience, these terms lead to six different results depends on the order they take place: interaction, identity, expansion, concentration, process and freedom [27].

Makkah`s center development -the case study in this paper- aims to clarify the relationship between landform and urban identity. Basically, Landform is one of the main elements that distinguishes Makkah from the other places and gives the city its identity [3]. However, many changes have taken place in its urban environment; especially, in the city 's center. This development affects the landform configuration. Shamiya District is one of the oldest areas in Makkah`s center and well known for its landform configuration. This configuration has changed in past years [28].

This paper consists of Four main parts: (1) The literature review discusses the aspects of place identity from the system approach then the impact of the landform on these aspects; spatial experience and cultural representation is determined. (3) The methodology clarifies the procedure of using space syntax theory to investigate the impact of the tangible aspect (landform) on urban identity from the system approach perspective. (4) The case study consists of two parts. The First part reviews the historical urban development of Makkah and focuses on the Shamiya last development. The second part discusses the comparative analysis results and explains them in the light of the literature review.

This research shows that the landform has a strong effect on the urban identity. This impact strengthens the identity that rises from the cultural representation. Highland gives the area more local attributes that distinguish the area from the knowledge of global structure. However, Highlands weakens the degree of city legibility because it cracks the visual accessibility and it gives areas local attributes that have low symbolic patterns.

\section{Literature review}

\subsection{Place Identity from system approach}

Part of the human identity comes from the physical aspect of the place. The place provides a supportive physical environment which creates systematic actions and situations day after day. As a result, this experience becomes a part of human identity [27]. Meanwhile, this interaction is considered as an ecological factor that shapes the environment and gives its identity. This ecological factor depends on functional and social objectives. Thus, the human is defined by the places where he lives. Similarly, place is defined by the human who uses it [6].

Consequently, place identity has two main aspects. The first aspect which is related to the individual comes from the daily experience of place. Experience is the core of identity. The strongest meaning of place is achieved by being part of it [23] because experience is a personal micro-narrative that strengthens the relationship between the human and his environment [24]. Observer experiences the place by defining it by different features in different levels. Space is defined by the image or surface, then by individual space and 
finally by the asynchronous complex relations. This asynchronous complex of relations comes from the second aspect of place identity [12].

The second that is related to the physical environment, is represented in the force that creates the physical environment. It is represented in the arrangement of urban elements that reflect certain lines of cultural force which represents the combination of circumstances that represents the city `s character [7]. These forces can be divided into two main objectives: functional and social objectives. A functional objective represents materials and elements which define the purpose of the place and its range. A social objective appears when the place is in social use. It represents cultural identities which are known and perpetuated. landscape's elements and their order are important aspects in cultural identities of places [12]. These two objective create cultural representation that supports the uniqueness of place through creating space of exclusion which is formed of segregating different culture depending on social power [23] [14]. The first geographical expression is territorial which materialized in small scales [23]. In larger scale, it appears in boundaries which determine the insider to give a sense of belonging and allow him to act subjectively and distinguish the outsider to push him act objectively [6]. This action comes from the place itself because it preserves the tradition as it is the source of original attitudes and saves what happened in the past through tangible and intangible aspects which clarify the meaning and feeling of collective identity [29].

\subsection{The influence of landform on spatial experience and cultural representation}

Landform impacts the urban identity in its two aspects i.e. cultural representation as well as spatial experience. Firstly, cultural representation: Landform structure at macro scale impacts the city configuration. This city configuration is determined according to basic elements of landform structure: Patches, Corridors and matrix. Corridors and patches determine the zoning of habitat and the main ways of movement [26]. Urban areas and transportation network are the bases of spatial model, governmental, economic and socio-demographic aspect of district life activities. Socio-demographic, spatial model, governmental, and economic aspect determine territory areas [26]. As a result, boundaries depend on landform in the urban structure. These boundaries determine cultural representation. In the same time, these boundaries play a role in separating the observer into "outsider" and "insider". Subsequently, it also affects spatial experience through boundaries [18].

Secondly, Landform impacts the city's experience at the micro - scale through city image. Landform impacts city image according to its features. In landform with strong features, the urban elements are more organized than flat landform. Highland reinforces urban elements strength [16] as follows:

- Edges: Highland is sharply defined with strong edges.

- Nodes: is distinguished by its location in highland [17].

- District: is distinguished by highland character.

- Path: Paths with high levels of highland have a dramatic view and experience [16].

According to Alexander (2002), City identity experience highly evokes when the city is perceived as a whole structure which integrates with landform structure. City consists of centers from which the city is perceived depending on the position of the observer. If the center is among a vivid system, it evokes a strong sense of belonging. Landform configuration is a natural vivid system that impacts city perceiving [1]. 
In addition, the Landscape impacts the urban identity from a third perspective. City identity is affected in levels depending on the degree of landform domination: City's character is related to the landform in case of strong and unique geographical features. In this case, the city is distinct after landform categorization which impacts the culture of its residents [32]. On the other hand, in the case of indiscriminate geographical features landform is defined after the cultural aspect [30].

\section{Methodology}

Space syntax is the tool used to measure the urban identity transformation in Shamiya district because space syntax is used to analyze urban places as a system. Hence, the procedure used in the space syntax analysis is representing and quantifying the aspects of the built environment. These results are used as the independent variables in a statistical analysis of observed behavior patterns [21]. Then, a comparative analysis is conducted between the spatial configurations before and after the Shamiya project took place. This comparative analysis is done to investigate the urban identity transformation.

To clarify the relationship between urban identity and landform, the two aspects of urban identity i.e. cultural representation and spatial experience are measured by space syntax. The first way which is used to measure cultural representation, determines the local and global characteristics of spatial configuration. The spatial configuration divides the observer to an outsider and an insider according to configurational knowledge [23]. Configurational knowledge consists of two complementary sets of spatial knowledge in the process of spatial learning in everyday experience; the intuitive knowledge of a more actual environment at a perceptional level and the knowledge of global structure at a cognitive level, resulting from long-term exposure to the built environment. An obvious structure is grasped immediately. Complementary to this, the potential structure allows one to gradually construct a more complex image. The former is spatial knowledge of the immediate environment- referring to the configurational knowledge- and the latter relates to the more global configurational knowledge, coming from a global context. The syntactic identity of a place is investigated by comparison between the degrees of global and local integration between the two systems within their global context.

The second way which is used to measure spatial experience, determines the degree of legibility. According to Lynch (1960), The image of the city depends on five elements i.e. nodes, paths, district, landmark and edges. These elements are put in three categories: polygons (districts), lines (paths, edges) and points (landmarks and nodes) [17] [15]. Legibility is the ease with which a system's elements are recognized and organized into a consequential pattern. If a city is legible, it can be visually grasped as an analogous pattern of distinguish symbols. Therefore, a legible city is a city whose districts or landmarks or pathways are easily discernible and grouped into an overall pattern. Intelligibility is analytically and quantitatively the qualitative aspect of spatial form [11]. The intelligibility of the form is measured by analyzing the relationship between how spatial configuration is seen from its parts and what it is like as an overall pattern i.e. as a distribution of integration. The metric for intelligibility is developed by correlating of global measure spatial configuration with a local measure. This notion is clarified by using a scatter diagram that shows the correlation between them and explains that reading the degree of intelligibility is by looking at the scatter. If the points shape a straight line rising at 45 
JES, Assiut University, Faculty of Engineering, Vol. 44, No. 3, May 2016, pp. $322-333$

degrees from bottom left to top right, it means that every time a space is more connected, then it would be more integrated [15].

\section{Study}

\subsection{Case Study: Makkah, El Shamiya District Project}

Makkah is selected as a case study due to two reasons. First, Makkah has been known for its dominate topography that distinguishes its spatial configuration from other cities [3]. Second, Makkah has been undergoing profound and large scale changes through the last decades. This provides two of the same location with and without the highland impact.

Basically, highland is one of the physical fundamental principles in Makkah that is applied to both individual landscapes as the underpinning land for structures. The geomorphology has determined the unique urban pattern of the Makkah metropolitan city, which has sprawled in radial direction on the confined surface areas of the complex silt channels. Makkah metropolitan is separated by steep mountain ranges. The valley of Makkah that dissects the mountain ranges is characterized by complex and interlocking patterns. Thus, the restricted attachment of neighbourhoods, were overcame through tens of tunnels and rock-cut corridors through these mountain ranges [3].

Historically, Makkah has passed through different forces which formed its urban fabric. The first was vernacular pattern and the second has been graduated from vernacular to political pattern. This transformation happened due to its religious value. Makkah is an old historical and religious place which has attracted many people from different cultures, especially after the appearance of Islam. Before $1955 \mathrm{CE}$, the urban fabric in Makkah consisted of official buildings and traditional houses, traditional houses were nearby valleys. They have two main types: "A'shes" which were made of light palm leaves and The "Sandaqah" was a wooden truss structure with two layers of walls. The inside shots were made of palm leaves creating a heatproof layer. These houses were inhabited by the regional migrants and pilgrims. After $1955 \mathrm{CE}$, these houses turned into permanent structures because theses migrants became residents. Cement has been used and houses were located upon the deep slopes of the mountains and became part of the city's perceptual image. These houses were vernacular architecture which is characterized by cultural diversity. With the rise of the nation state, the transnational identity of Makkah was localized because nation states operate within their boundaries at the local level while religious centres holiest destinations function at the universal level. The new approach to modernization was achieved by developing architectural aesthetics through cultural transfer to relate architecture to Muslim heritage with the use of modern materials and technology [31].

Because of the evanescence of land section suitable for urban development, it is now common in Makkah to cut the piedmont and foot slopes of the neighbouring mountains in order to create new suitable plots for buildings, especially in the areas near the Holy centre. Similarly, the foot slopes of the mountains bordering the Holy places were also cut to provide wider flat areas [3].

Recently, there are two main projects taking place in the centre of Makkah to provide more spaces and infrastructures for millions of pilgrims that gather annually for a few days to perform Hajj [3]. El Shamiya district project and Gabal Omar project

El Shamiya district was one of the oldest districts in Makkah. It is located on the north of the holy mosque and lies on hills at $280 \mathrm{~m}$ height. It consists of many neighbourhoods; 
El-Gaza neighbourhood, it contained traditional houses and had been inhabited by Syrian (Shamiyan) traders. Gaza market was a traditional and old market with ancient and traditional features. Urban design of El Shamiya has been characterized by carved and disconnected streets, Figure (1) [5].

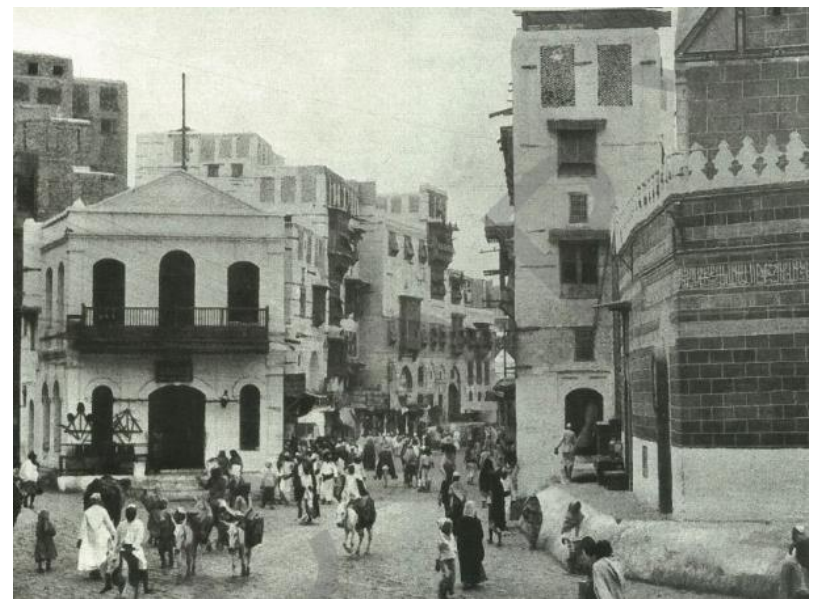

Fig 1.The old Shamiya `s streets are carved and disconnected streets (Atlas Makkah, 2005)

Recently, El Shamiya transformation project: The expansion project is bordered by the northern boundaries of Al-Holy mosque and includes parts of the old districts next to the Holy Mosque from the same side. Those areas include parts of Al-Shamiah, Al-ararah, Al-Mudda'a districts and the area extending from Al-Mudda'a District to the northeast of the Grand Mosque in

Al-Shamiah District and Harat Al-Bab to the northwest of the Holy Mosque. The expansion begins from the Holy Mosque Street on the east and extends east in a crescent shape up to Khalid Bin Al-Waleed Street, and westward in Al-Shubaikah, Figure (3)

The expansion project turns the natural highland of Shamiya to gradual paths. The streets have been categorized into three elements; (1) the main footpath axes, (2) the hotel course, which includes three levels separated by (3) a wide road for cars, surrounded by a group of hotels aligned in graduation and overlooking the holy mosque. In addition, the land use has changed to multi use building. The major uses are hotels, commercial activities and shopping, Figure (2) [20].

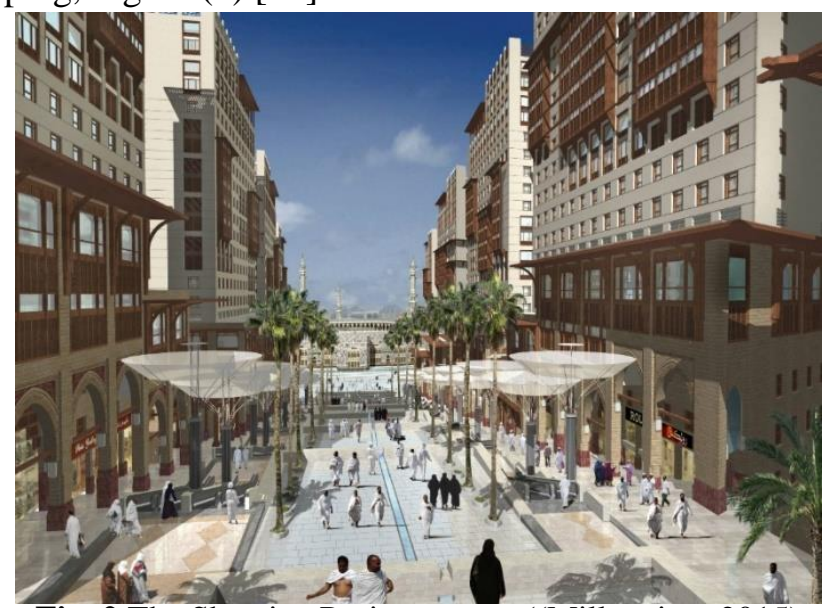

Fig. 2.The Shamiya Project streets ((Millennium,2015) 
To determine the role of highland on El Shamiya urban identity, a comparative analysis between the old Shamiya and the supposed Shamiya project (2020) takes place using space syntax tool analysis and depending on the previous argument (Applications of space syntax).

The map of Shamiya 2004 on which this research depends is from the satellite Google earth pro ${ }^{\circledR}$. The master map of El Shamiya project 2020 is from Millennium, 2015 [20]. The case study aims to analyse the impact of landform. Thus, Rhinoceros 5 software is used because it provides a 3Dimension (Taking the height factor in consideration) capability in the analysis process. Space syntax theory application is drived by Grasshopper ${ }^{\circledR}$ plugin - Decoding space ${ }^{\circledR}$ libraries. These libraries provide the local and global integration values, from which the degree of integillity is measured, Figure $(3,4)$

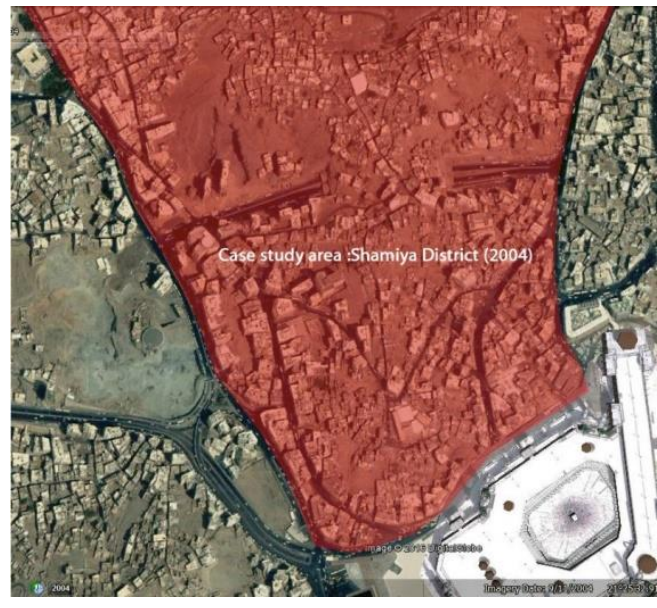

Fig 3. El Shamiya `s district in $2004 \mathrm{CE}$ (Google earth, 2004)

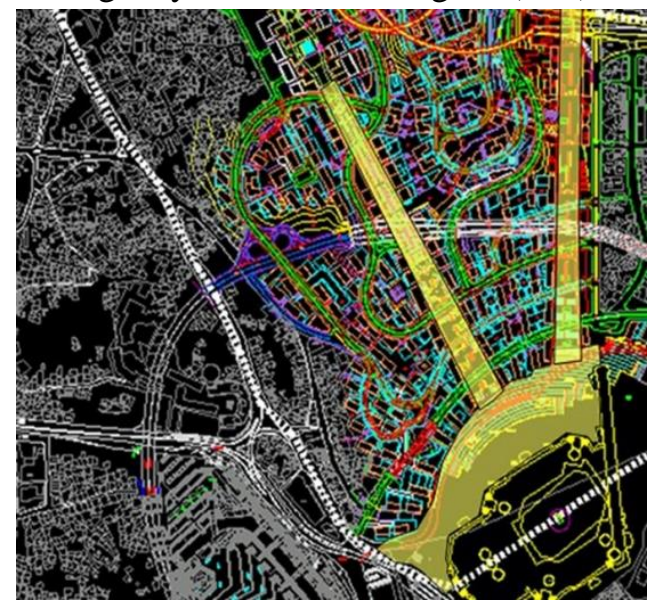

Fig. 4. El Shamiya `s project which is supposed to complete in $2020 \mathrm{CE}$ ((Millennium, 2015)

\subsection{Discussion}

Table (1), shows the difference in the degree of global and local integration between the two systems within their global context. Shamiya 2004 is locally more integrated at .013962 than that of Shamiya 2020 at 0.007681. As for global integration, there is big difference between the two areas. Shamiya 2015 with global integration of 0.551502 , is more globally integrated than that of Shamiya 2004at 0. 551502.

\section{Table 1.}

Local and Global Integration and intelligibility of El-Shamiya 2004 and 2020(By Author)

\begin{tabular}{|l|l|l|l|}
\hline Area & Local Integration & Global integration & Intelligibility \\
\hline El-Shamiya 2020 & 0.007681 & 0.551502 & 0.229 \\
\hline El-Shamiya 2004 & 0.013962 & 0.348486 & 0.2702 \\
\hline
\end{tabular}

These results refer to the spatial configuration of Shamiya 2020 district which has more global attributes that can be identified by both an insider and outsider observer. This global attributes come from the designer using straight streets with well-known shapes in designing the street network, Figure (6). However, the old Shamiya district has higher complex image that creates more local attributes that distinguish this district from the global structure attributes, Figure (5). This complex image comes from the vernacular architecture of the district. This architecture has been affected deeply by highland configuration. Thus, it can be 
concluded that the presence of highland creates more local attributes than the case of its absence. This local attributes give a sense of identity to the space [15].

Moreover, the scatter diagram of both Shamiya 2020 and 2004 show that both are relatively intelligible because the points shaping the straight line are raising less than 45 . Nevertheless, the degree of its relative intelligibility is variable there. The scatter diagram of Shamiya 2020 indicates that its spatial structure is more intelligible because there is a stronger relationship between global and local integration, indicating an unclear relation between the global and local structure at an r-squared of 0.229, Figure (5). However, the scatter diagram of the Shamiya 2004 indicates that the spatial structure of this area is less intelligible. The regression line is steeper than that of the whole area, suggesting a poor relationship between global and local integration. Thus, the area is much less intelligible within the global context at an r-squared of 0.2702, Figure (6).

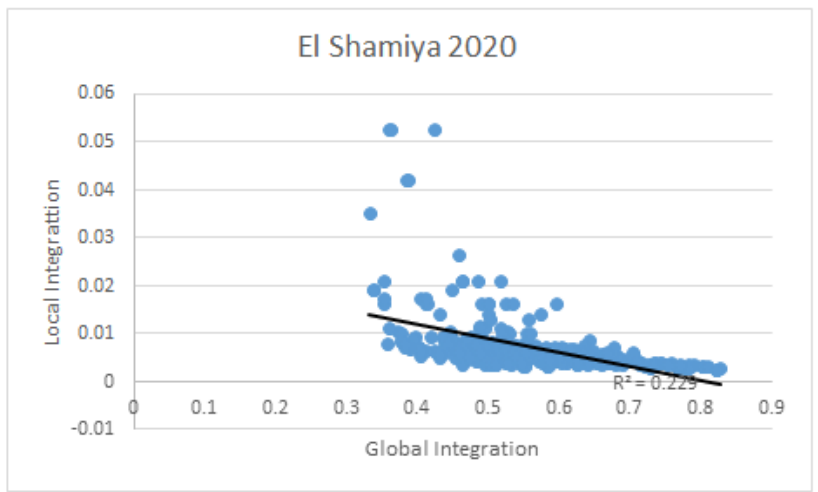

Fig. 5. Scatter Gram of intelligible, El Shamiya 2020(By Author)

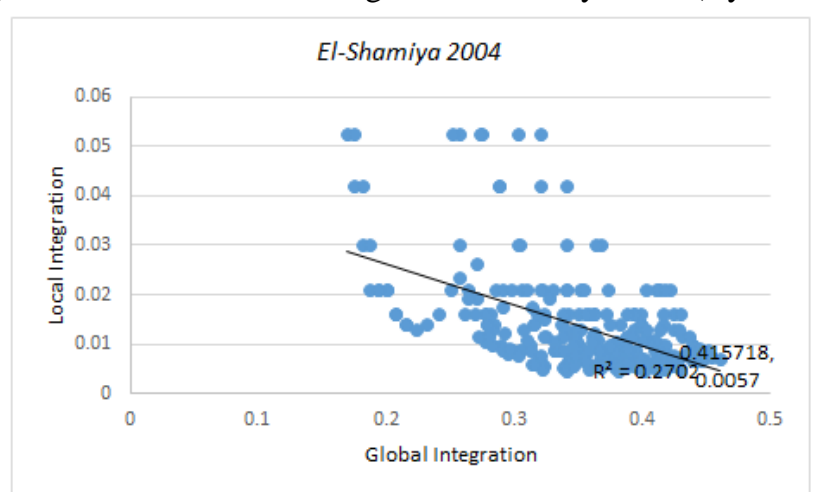

Fig. 6. Scatter gram of intelligible, El Shamiya 2004(By Author)

These results show that spatial configuration of the Shamiya project part is more manifested than old Shamiya parts. The designer in Shamiya project used a straight street in addition to the absence of highland levels which allow more obvious visual accessibility [22]. Besides, the connectivity of streets on hills (Old Shamiya) is lower than valleys, because the highland configuration and its different levels limit the extensions of the streets [8]. Moreover, Old Shamiya has more local integration that creates fewer patterns of distinguished symbols among its spatial configuration. However, the Shamiya project has a global pattern with distinguishable symbols. Thus, the legibility on Shamiya project is higher than in old Shamiya. 
Beforehand, Literature review argument shows that the landform impacts urban identity through two dimensions as following:

1- Boundaries depend on landform in the urban structure. These boundaries determine cultural representation. In the same time, these boundaries play a role in separating the observer into "outsider" and "insider". Subsequently, it also affects spatial experience through boundaries [18].

2- Landform impacts city image according to its features. In landform with strong features, the urban elements are more organized than flat landform. Highland reinforces urban elements strength [16].

The results support the first dimension and deny the second dimension as following:

1- This case study`s results (Local and Global Integration and intelligibility of ElShamiya 2004 and 2020) support the role of landform in determining boundaries. These results show that in the case of highland, the landform configuration sharply separates the spatial configuration from global integration. This separation comes from more local attributes that are given by natural pattern of landform. Besides, the present of levels in El-Shamiya 2004 support the natural pattern to play a role in determining the boundaries. In contrast, In Shamiya 2020, The natural pattern turns into a gradual land. This gradual land lacks of the local character of natural pattern and the levels of high land that separated each area from others.

These findings accord with the previous studies that reports "on highland quality and properties of site, affect the size of the building by regulating the relations between one to the others. Natural slope (above 30\% slope) creates an internal relationship are important, especially in terms of access. It can be added to the visual potency depending on the levels. The natural quality is a good way to observe the area at the appropriate scale." [22].

2- The results of the scatter diagram of both Shamiya 2020 and 2004 show that the city imageability becomes less in the case of highland domination. the urban elements are more organized than flat landform. Highland reinforces urban elements strength [16]. But the case study analysis proved that the city as a whole is less imageability in the case of highland domination. That leads to conclude that the city elements are reinforced as a separated element not as a whole.

This finding supports the opinion of Alexander (2002) that states that city identity experience highly evokes when the city is perceived as a whole structure which integrates with landform structure. The city consists of centers from which the city is perceived depending on the position of the observer. If the center is among a vivid system, it evokes a strong sense of belonging. Landform configuration is a natural, vivid system that impacts city perceiving. In the case of high land, the levels impact the degree of connectivity effects the experience the city as a whole [1].

Thus, Shamiya as a case study shows that the highland has a strong effect on the urban identity. This impact strengthens the identity that rises from the cultural representation. Highland gives the area more local attributes that distinguish the area from the global character. However, landform`s impact weakens the degree of city legibility because it cracks the visual accessibility and it gives areas local attributes that have low symbolic patterns. 
In addition, the old Shamiya district was a part of Jabaal Omar. This district was called Jabaal Omar this naming came from an old story attached to the high level of this mountain. Nowadays, this district is named (El-Shamiya project) or the extension. These two names are not attached with landform configuration.

The change of the district name insured that city's character is related to the landform in case of strong and unique geographical features. In this case (highland), the city is distinct after landform categorization which impacts the culture of its residents [32]. On the other hand, in the case of indiscriminate geographical features landform is defined after the cultural aspect [30].

\section{Conclusion}

Urban identity is one of the psychological dimensions of the cultural pattern that evokes from the overlapping of the events pattern and the physical aspect. Such overlapping creates an analogy relationship between the physical and the intangible aspect. A sense of urban identity evokes through the cultural representation and the spatial experience that affect the spatial configuration. Firstly, cultural representation represents cultural identity through boundaries because it evokes a sense of exclusiveness. Secondly, spatial configuration determines the spatial experience that is considered the core of place identity.

Highland affects the spatial configuration. Subsequently, it affects the urban identity. Landform determines the boundaries and affects the spatial configuration that in turn determines the spatial experience.

The role of physical aspect of the urban identity is analyzed through the cultural representation and the place attachment. These two aspects are represented through the local and global characters and the degree of legibility that are represented on the spatial configuration. Spatial configuration can be analyzed by space syntax. This method is used in this research to make a comparative analysis between identity of Shamiya district before and after the project in order to determine the degree of urban identity transformation.

From the results, it can be concluded that Shamiya's urban identity is affected by the urban development because this development affects the highland configuration. These changes transform Shaniya's urban identity from one that depends on the identity of cultural representation to another that depends on city imageability.

\section{REFERENCES}

[1] Alexander. Christopher. (2002), The nature of order, Oxford University Press, USA.

[2] Alexander. Christopher, (1979), The Timeless Way of Building, Oxford University Press, USA.

[3] Al Harbi. Khalid\& El Bastawesy.Mohammed, \&Habeebullah.Turki, \&Mandour.Mousad(2012), Assessment of Landslides of the Hillslopes in Makkah Using Remote Sensing and GIS, The Journal of American Science,8(3)-(pp.49).

[4] Antrop. Marc, (2005), why landscapes of the past are important for the future, Rural Landscapes: past processes and future strategies,70,(1-2000,(pp .21-34).

[5] Mi'rāj ibn Nawwāb .Mirzā (2005), Ațlas kharā'iț Makkah al-Mukarramah:< http://www.arabicbookshop.net/main/details.asp?id=226-428>.

[6] Casakin.Hernan \&Bernard. Fátima ,(2012). The Role of Place Identity in the Perception, Understanding, and Design of build environment, Bentham books.

[7] Cullin.Gordon,(1961),Concise Townscape, Routledge.

[8] Cutini. Valerio (2007), Axial lines and contour lines: climbing up the center. University of Pisa, Proceedings. 6th International Space Syntax Symposium. İstanbul. 
JES, Assiut University, Faculty of Engineering, Vol. 44, No. 3, May 2016, pp. $322-333$

[9] Grasshopper, (2015): < http://www.rhino3d.com/download/grasshopper/1.0/wip/rc>.

[10] Google earth, (2004, September 11). V 1.3.29.5. Saudi Arabia, [map], $21^{\circ} 25^{\prime} 27.39^{\prime \prime}$ N, $39^{\circ}$ 49' 35.04” E, Eye $1023 \mathrm{~km}$, Eye alt 5203F km. Retrieved from http://www.earth.google.com

[11]Hillier B. (1999), Space is the Machine: A Configurational Theory of Architecture, Cambridge; Cambridge University Press.

[12] Hillier B. and Hanson J., (1984), The Social Logic of Space, Cambridge; Cambridge University Press.

[13] Jackson.John. Brickerhoff. ,(1984). Discovering the Vernacular Landscape. Yale University press. London.

[14] Knox.Paul\&Pinch.Steven., (1982). Urban Social Geography, Taylor \&Francis, Routledge press, USA.

[15] Kim.YoungOok,(2001). The role of spatial configuration in spatial cognition. University of Sejong. Korea.

[16] Lynh.kevin.,(1984).Theory for good city. Cambridge, Ma: MIT press.

[17] Lynh.kevin ,1960, The image of the city, Cambridge, Ma: MIT press.

[18] Makhzouumi.Jala\&Pungetti.Gloria.,(1999).Ecological Landscape design and Planning . London; Routledge Press.

[19] Motlach.John.L,(2000).Introduction to Landscape Design, Toronto: John Wiley \& Sons.

[20] Millennium,(2015): 〈http://www.millenniumdev.com/ProjectsDetails.aspx?pageid=310\&parentMenuID=367>

[21] Penn. Alan, (2001), Space Syntax and Spatial Cognition or, why the axial line? 3rd International Space Syntax Symposium. Atlanta.

[22] Ramadanta. Asyra\&Darjosanjoto. Endang Titi SunartiB,(2012), Application of Space Syntax as Presentation and Analysis Technique in the Study of Spatial Integration in Contoured Landform , Journal of Basic and Applied Scientific Research, Indonesia.

[23] Rose. Gillian, (1995). Place and Identity: A Sense of place. Oxford University. London.

[24] Roca. Zoran\&Claval .Paul,\&Agnew. John A., (2011), Landscapes, Identities, and Development, Design and Patent Acts. United Kingdom.

[25] Rhinoceros 5, (2015): https://www.rhino3d.com/download/rhino/5/latest

[26] Selman. Paul, (2012). Sustainable Landscape planning: The reconnection agent. Routledge press. London.

[27] Seamon.David , (2008), "Intensify this Awe": Threeness, the Triad, and Christopher Alexander. Environment Design Research association, Mexico.

[28] Staff.Lee\&Schneider. Jens\&Angawi. Sami\&Angawi. Ahmad,2001A New Terrain Modeling Technique for Digital Reconstruction - a case study,King Abdullah.

[29] Tengberg\& Susanne. Fredholm, \&Ingegard. Eliasson ,\&IgorKnez\& Katarina. Saltzman,\&OlaWetterberg , ( 2012). Cultural ecosystem services provided by landscapes: Assessment of heritage values and identity, Ecosystem Services journal, 2, (pp 14-26).

[30] Sun-young. Rieh. (2003), Boundary and Sense of Place in Traditional Korean Dwelling, Sungkyun Journal of East Asian Studies,3(2), (pp. 62-79).

[31] Schnoor. Christoph, (2014). Saudi National Identity versus Makkah Transnational Identity, Unitec e-Press. New Zealand.Auckland,31, 15-26.

[32] Walliams .Maia\&Kuhun .Werner\&Painho.Marco , ( 2012).The influence of landscape variation on landform categorization.Journal of spatial information science.5, (pp. 51-73) . 


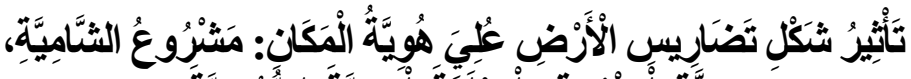

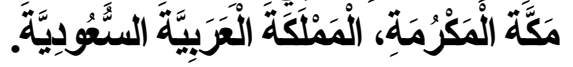

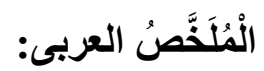

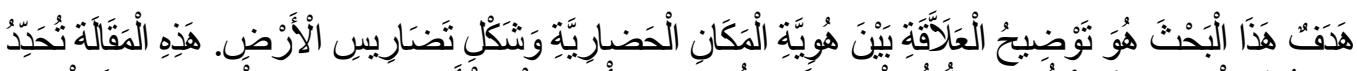

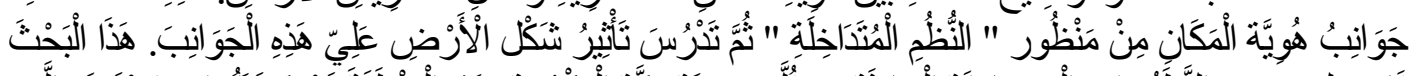

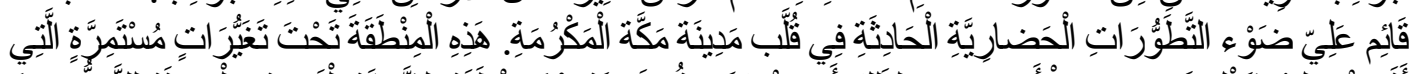

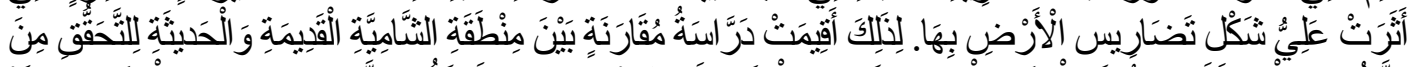

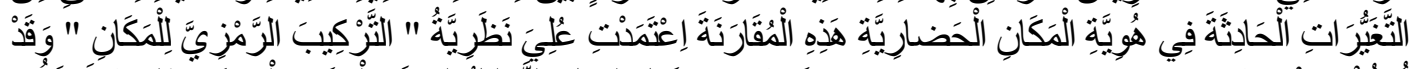

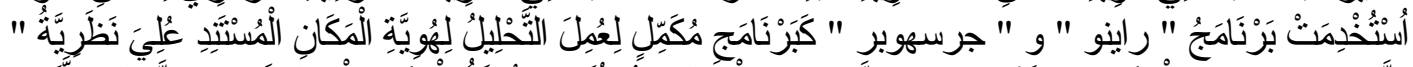

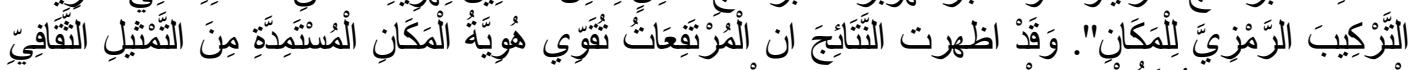

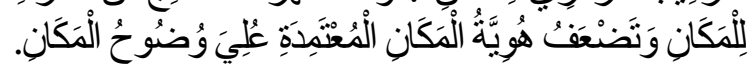

